\title{
DiSCOURSE-DRIVEN MEANING CONSTRUCTION IN NEOSEMANTIC NOUN-TO-VERB CONVERSIONS [MEANING CONSTRUCTION IN NOUN-TO-VERB CONVERSIONS]
}

\author{
RAFAE AUGUSTYN \\ Maria Curie-Skłodowska University in Lublin, Poland \\ augustraph@gmail.com
}

\begin{abstract}
Neosemantic noun-to-verb conversions such as beer $\rightarrow$ to beer, door $\rightarrow$ to door, pink $\rightarrow$ to pink, etc., constitute a particularly interesting field of study for Cognitive Linguistics in that they call for a discourse-guided and context-based analysis of meaning construction. The present article takes a closer look at the cognitive motivation for the conversion process involved in the noun-verb alterations with a view to explaining the semantics of some conversion formations in relation to the user-centred discourse context. The analysis developed in this article draws from the combined insights of Fauconnier and Turner's (2002) Conceptual Integration Theory and Langacker's $(2005,2008)$ Current Discourse Space.
\end{abstract}

Keywords: conversion, cognitive linguistic, conceptual integration, discourse space

\section{Introduction}

Cognitive Linguistics holds that meaning is something that speakers get from both linguistic and non-linguistic inputs, relying on contextual and background knowledge (cf. Coulson 2001, Langacker 2008). Indeed, it seems that one cannot satisfactorily account for the meaning construction process unless (i) the encyclopaedic view of semantics in the sense of Langacker (1987, 1991) and Taylor (2003) is envisioned, (ii) Fauconnier and Turner's (2002, 2007) Conceptual Integration Theory (CIT) (see also Libura (2007), accounting for different domains of the conceptualiser's knowledge representation, is adopted and (iii) Langacker's $(2005,2008)$ notion of the Current Discourse Space $(C D S)$, which emphasises the role of speaker-hearer interaction, is applied in the meaning construction analysis.

With these theoretical considerations in mind, we address the question of how to account for the 'neosemantised' meanings of denominal verbs. The paper argues that in order to fully grasp new ideas residing in novel expressions which code the human cognitive experience of the world and arise, inter alia, via 'neosemantisation' processes, meaning should principally be analysed with reference to both the conceptualisations that give rise to it and to the context-dependent interpretation of it (cf. Kemmer 2003, 
Kardela 2006). In particular, it is claimed that CIT and CDS form a joint semantopragmatic interface which can ensure proper, context-dependent interpretation of 'neosemantic' verbs. ${ }^{1}$

\section{Conversion as a creative force in language}

The world, which language users inhabit, is a constantly evolving environment, not only in its physical dimension, but also in terms of conceptual contents that may be conveyed by the conceptualising subjects. However, the speakers are commonly faced with the dilemma that most conceptualisations they wish to symbolise are most probably unique and lack vocalised representations. Hence, in need of responding to new experiences people, having only a limited language repertoire at their disposal, are expected to categorise new abstract conceptual constructs in terms of already available resources, i.e. they reuse established linguistic items to encode new concepts and ideas. Such innovative 'recycling' of the overall repository of lexical units may take a number of different forms, e.g. through derivational processes involving novel combinations of free morphemes (compounding) or the attachement of bound morphemes to free morphemes (affixation), merging two or more lexical items into one novel unit (lexical blends), clipping or abbreviation, reduplication of syllables or single letters, syntactic alterations of component elements, etc.

Yet another process that enables language users to convey novel concepts by virtue of conventionalised lexical units, with no apparent change in the morphological composition of the lexical items, is conversion. A particularly interesting case of conversion is the lexical alteration of the type noun-to-verb conversion, a process which produces adnominal neosemantic verbs.

The study presented here is illustrated by the selected examples from the corpus of over 200 very recent neosemantic noun-to-verb conversions encountered, inter alia, on the Internet fora and in online articles. In order to account for the meanings of these neologic conversion formations we also made extensive use of the explanations provided in the online resources: Urban Dictionary (retrieved February 10, 2011, from http://www.urbandictionary.com/), a vast repository of modern slang, and the Rice University Neologisms Database (retrieved February 10, 2011, from http://neologisms.rice.edu/index.php), Suzanne Kemmer and her students' project, both of which collect up-to-date new-fangled linguistic expressions that emerge as products of creative English speakers' language usage, as well as attempt to partially explicate and interpret them. For each case of novel verbal conversion adduced below we limit ourselves to present only the immediate textual environment, i.e. usually a sentencelength co-text, in which a particular neologic form appeared. The following examples provide merely a general overview of the process we have analysed:

\footnotetext{
${ }^{1}$ For the purpose of our study we use the notions of neosemantism and neosemantic in the similar vein to Herberg and Kinne (1998: 1-2) who characterise neosemantisms as lexical units that in a given language had already had an established (conventionalised) meaning, but to the same form a new meaning was assigned by language users (cf. inter alia Grabias 1980: 85-86 and Elsen 2004: 21-23).
} 
(1) Hey man, can you beer me the television remote?

[to beer - to hand or fetch something]

(2) Don't forget to blitz me sometime and I'll write back.

[to blitz - to write an e-mail]

(3) She's such a golddigger. She only dates him because he's caking her.

[to cake - to buy someone everything they want]

(4) He totally jocks you.

[to jock - to have a heavy crush on someone]

(5) a. That person's been swining around me lately.

b. I think he's going to swine next, so I'd steer clear.

[to swine - to have swine influenza]

(6) a. So here is where I need help: I came back home Monday and totally spaced her birthday (which was Monday)! She didn't say anything until Today!

b. Dude, I totally spaced Grandma's funeral!

[to space - to forget something]

(7) One day Jeff woke up and felt totally porched by all his friends. They had been windowing him for weeks and he couldn't stop them. He knew that eventually the worst would happen... he would be doored by all for what they knew of him.

[to porch - to shun someone, to set something temporarily aside]

[to window - to look into someone's life from the outside]

[to door - to permanently exclude someone, to discard something]

In the following, we shall argue that the examples listed above, as well as any other examples of novel noun-to-verb conversions, are "a suitable mirror of intelligent human behaviour" revealing intelligent creative behaviour that "exploits basic knowledgeresources and the information processing capacities of the human mind" (Langlotz 2006: 10). In all examples cited, the neosemantic verbs employed could be easily replaced by conventional expressions (e.g. the verb to cake in sentence (3) might be as well substituted by the phrase "to indulge one's whims"), it may be rather the case that people use such creative conversions as a means of expressing themselves in an interesting or entertaining manner. This may be an important part of information the speakers wish to communicate using a given neosemantic verb, apart from the uniqueness of their conceptualisations. It appears that neosemantic noun-to-verb conversions do not merely serve a decorative role in a text; they often serve as dense descriptors that convey a great deal of information in a single lexical design. (cf. Veale and Butnariu 2010: 399). 


\section{The cognitive basis for conversion}

Within mainstream linguistics conversion is held to constitute a special case of derivational morphology. ${ }^{2}$ Whereas in standard derivation cases an affix is added to a stem, in the case of conversion the stem takes a zero form, i.e. "one that is present, but not perceptible" (Dirven and Verspoor 2004: 64). Similarly, Katamba (1994) recognises conversion as a type of derivational process, noting that

[...] in English very often lexical items are created not by affixation but by conversion or zero derivation, i.e. without any alteration being made to the shape of the input base. The word-form remains the same, but it realises a different lexical item. (Katamba 1994: 70)

It is noteworthy that no evident morphological change with simultaneous transition of a particular lexical item from one word class to another is the hallmark of conversion. For instance, the lexeme bank, apart from being a homonymous word, takes reference (for all its three homonyms) to two lexical categories. It may function as a noun or as a verb, and thus is associated with both the nominal and verbal meanings. Among its numerous senses, it denotes "a financial institution" or "a long raised mass of earth" (nominal senses), but also it means "to deposit money in a bank" or "to enclose with a bank" (verbal senses).

Twardzisz (1997: 41-61, 87-174), adopting a cognitive approach, views conversion as an intrinsically semantic phenomenon, analysing it in terms of a much broader process involving semantic extension through elaboration of a number of lower-level subschemas from more abstract schemas (e.g. [[PROCESS] $\rightarrow$ [THING]] or $[[\mathrm{THING}] \rightarrow$ [PROCESS $]])$ to sanction the instantiations of particular conversion formations (cf. also Langacker 1987, 1991; and Taylor 2003). Consider the extension schema

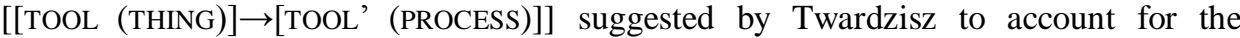
processual extensions of the thing-prototype tool in the following set of examples (after Twardzisz 1997: 101):

(8) a. Bob took two big planks and began to hammer them into a cross.

b. They nailed signs to the trees all along Lame Walk.

c. I'm going to brush my teeth.

d. They chained themselves to the fence.

e. I saw him whipping his team of mules.

Although semantic extensions of the sort discussed above are not entirely descriptively predictable, the lack of full predictability does not pose a problem for cognitivists (cf. Twardzisz 1997: 195). In particular, Langacker (1987 and elsewhere) repudiates the

\footnotetext{
${ }^{2}$ However, this view is not shared by all linguists. For instance, Lieber (2004: 93) argues against such treatment of conversion maintaining that "conversion does not behave semantically like derivation with use of [affixation]". Therefore, it is not a derivational process. Instead, Lieber proposes that conversion should be regarded rather as the process of relisting, i.e. the entrenchment of an old form-new meaning pairing and addition of the new entry into the lexicon. She claims specifically that "conversion occurs when an item already listed in the lexicon is reentered as an item of a different category" (p. 90). Such a claim is reminiscent of Clark and Clark's (1979) view of conversion as innovative language coinage.
} 
need for a linguistic model to be able to account for absolute predictability. Language, Langacker asserts, is intrinsically a psychological phenomenon, not a computational one (cf. e.g. Langacker 1991: 262).

To provide a cognitive framework for the investigation of conversion we shall take into account profiling, a fundamental cognitive operation involved in scene construal. An expression's profile permits us to establish what a particular expression actually designates, for it "stands out as the specific focus of attention within the immediate scope or conceptual base of this expression" (Langacker 2008: 66). Subsequently, we shall resort to Langacker's (2008: 103) proposal that "essential grammatical notions can be characterized semantically." It means that, for instance, the categories of nouns and verbs can be defined basically in terms of what they profile. Following Langacker (2008: $98,100)$ we shall say that nouns profile things, whereas verbs profile processes. Thus, from cognitive perspective, conversion from a noun to a verb appears to be commensurate with a shift in an expression's profile, i.e. within the semantic content of the evoked lexical item the focus of attention is relocated from the thing to the processual relationship as a whole. The alteration of this kind is conceivable, as first, things, although may be conceptually autonomous, usually participate in some relations, and second, processes always require some participants to occur. By way of example examine the sentence below:

(9) I am homeworking right now!

[to homework - to do homework]

In example (9), the action of doing homework presupposes two participants, an agent performing the action and the patient undergoing some transformation in the course of the action. In the analysed sentence the agent is pronoun $I$ who simultaneously is the trajector in the process of homeworking. The implicit, yet logical patient in the described action is the noun homework that at the same time is the covert landmark in the processual relationship not realised at the sentential level, but existent at the conceptual level (cf. also Twardzisz 1997: 90-96).

Certainly, as defined above, the schema [[THING] $\rightarrow$ [PROCESS $]]$ is a very general one lacking the descriptive predictability with reference to possible semantic extensions such conversions may produce. Owing to this, for most cases of noun-to-verb conversions, the semantic content of verbs converted from different nouns is underspecified to a great extent. However, this does not seem to pose a problem for actual language users, since the proliferation of novel verbal conversions bears testimony to the contrary. In fact, this opens up the possibility of virtually infinite unrestrained (creative) associations of different senses with adnominal verbal conversions, provided that the extended senses of these converted verbs are somehow sanctioned by their context of use. For instance, consider the verbal usages of the eponymous noun oprah in the following sentences:

(10) a. I never manage to mantain a stable weight. I always seem to oprah all time. [to oprah - to 'yo-yo' over and over again; the term alludes to Oprah Winfrey's battle with overweight] 
b. He was oprah-ing female insecurities to sell books.

[to oprah - to exploit someone or something; this verbal usage exposes the coiner's antipathetic attitude towards Oprah]

c. I: What is your most over-rated book?

MR: "The Corrections" by Jonathan Franzen. A book that started well and then totally overstayed its welcome. I hurled it against the wall in frustration. And then to see Franzen get "Oprah-ed" (i.e. sell heaps of books because one is selected for the Oprah Book Club) despite the fact that he dissed Oprah was just too much! Oprah made him and I doubt he'll write another big book again. [conversion self-explained by the coiner]

d. Covered in Cheetos dust, Amir oprahed on about losing weight, then heated up a burrito.

[to oprah - to announce you're going to do something, but then not to do it for two years]

Although the distinct senses of the verb to oprah listed above appear to be unrelated and the semantic content of the possible resulting extensions from the noun Oprah are rather unforeseeable, each of the senses illustrated with appropriate examples is motivated by a specific context of use and involves metonymic or/and metaphoric projections linking selected elements of the conceptual content of the source noun and converted verbs.

Recapitulating our theoretical considerations presented above and based on Langacker's (1999: 203-205) notion of conceptual arrangement, we could represent the conversion process schematically as a shift of an expression's profile (marked by bold lines) within the immediate scope (IS) of this expression attended by a speaker or hearer $(\mathrm{S} / \mathrm{H})$ acting as a conceptualiser encoding or decoding a particular linguistic utterance (see Figure 1.). Further, our claim is that in order to understand the utterance containing a novel conversion, the shift from profiling a thing to profiling a process must be recognised by the conceptualiser. 


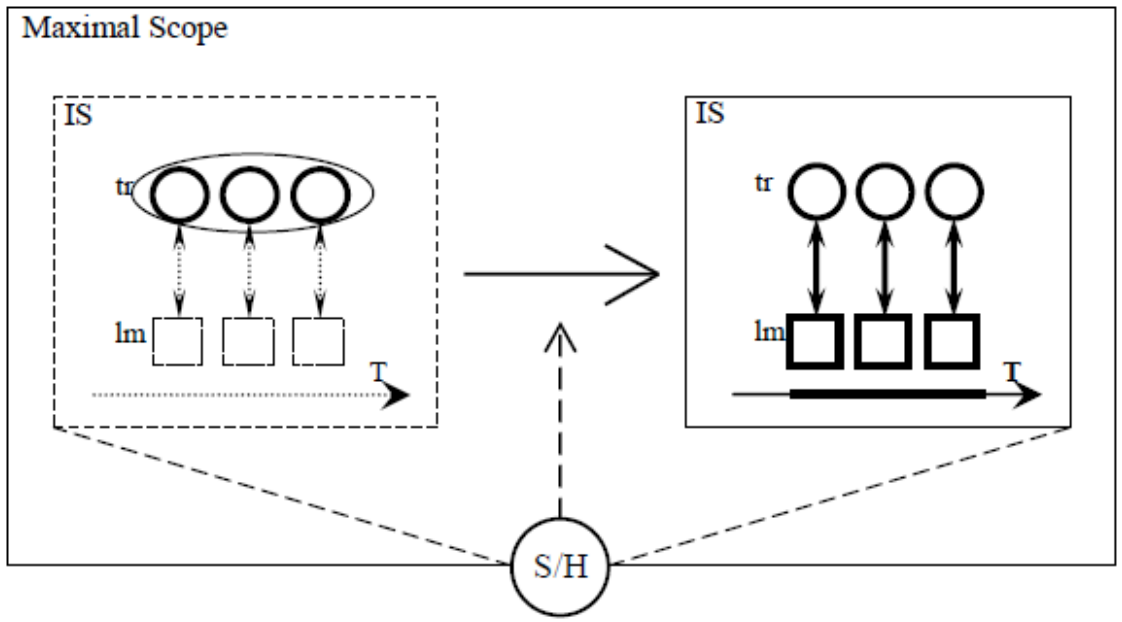

Figure 1: Schematic representation of thing-to-process conversion

Given the schematic representation of noun-to-verb conversion process the issue remains still unresolved of how to account for the meaning of novel instances of adnominal verbal conversions. In what follows, we propose a possible solution to the problem.

\section{Conceptual blending}

One of the approaches to model linguistic structure in the process of meaning construction is represented by the Conceptual Integration Theory (CIT, also referred to as Conceptual Blending Theory) as proposed by Fauconnier and Turner (1994, 1998, 2002), a theory which developed out of the theory of mental spaces as postulated by Fauconnier (1985, 1994).

Blending or conceptual integration "is concerned with on-line dynamical cognitive work people do to construct meaning for local purposes of thought and action" (Fauconnier and Turner 2007: 370). Put differently, the CIT aims at modelling the dynamic evolution of speakers' "on-line" representations through creation of networks of connections between mental spaces.

One may envisage mental spaces as "temporary containers", evoking relevant information about a particular domain and containing a partial representation of the entities and relations of a given factual or non-factual scenario as construed by a conceptualiser. In the process of conceptual blending, partial structure from two or more mental spaces is dynamically combined, i.e. selectively projected into a blended space. Blending processes unfold in an array of mental spaces known as a Conceptual Integration Network. A basic integration network model (as shown in Figure 2) consists of:

(i) two (or more) input spaces, containing relevant information from respective domains of knowledge representation that are linked on the basis of the so-called 
partial cross-space mappings (i.e. abstract correspondences between elements and relations in different spaces) connecting respective counterparts from separate inputs;

(ii) a generic space that represents abstract commonalities of the input spaces;

(iii) and finally, a blended space that inherits some structure from each of the inputs as well as novel emergent structure not available in both inputs.

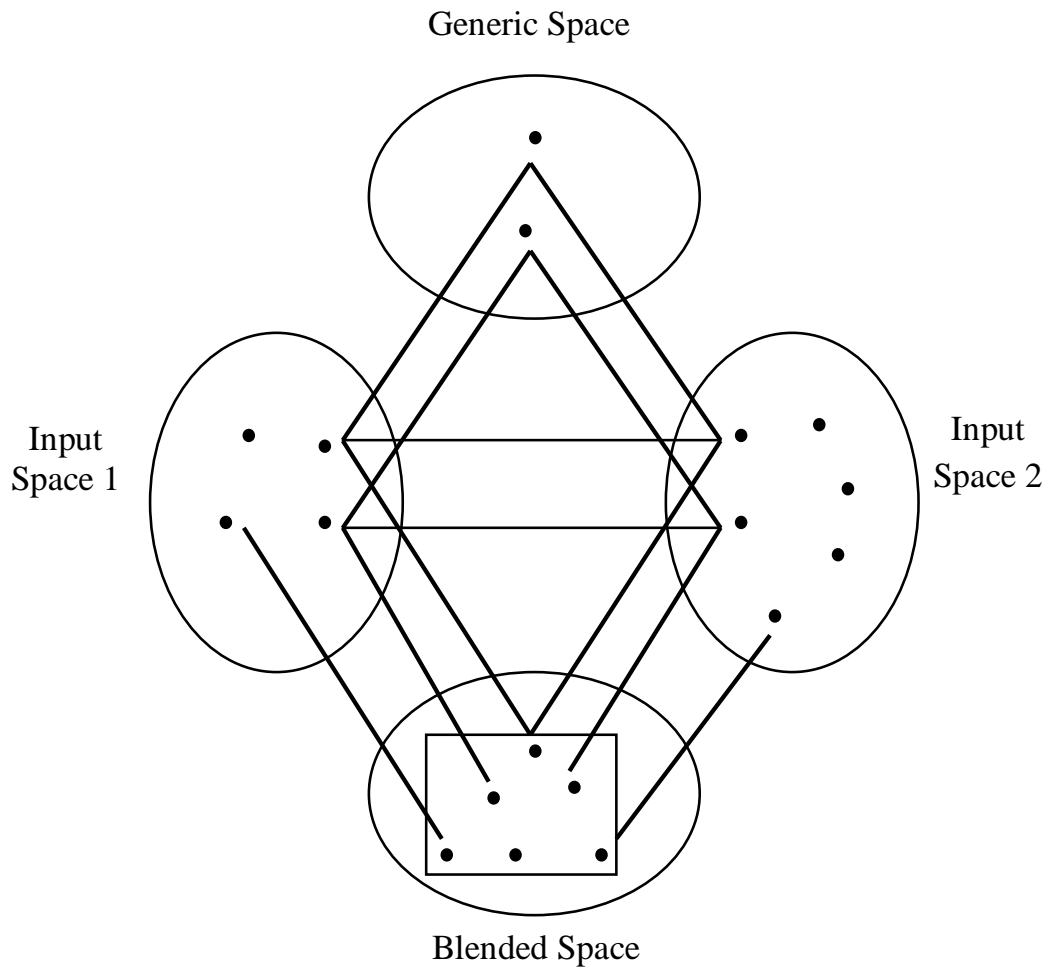

Figure 2: A basic integration network

To account for the dynamic meaning construction process and to explicate the emergent meaning, the CIT model exploits the activation of background knowledge and frequently involves the use of mental imagery and mental simulation (cf. Fauconnier 1997, Fauconnier and Turner 2002, Libura 2007). Nonetheless, the authors of the CIT caution against treating blending as a process generating unified interpretations of particular concepts. Rather, it should be regarded as a mental operation enabling infinite possibilities of meaning construal and interpretation.

Conceptual blending operates largely behind the scenes. We are not consciously aware of its hidden complexities, any more than we are consciously aware of the complexities of perception involved in, for example, seeing a blue cup. Almost invisibly 
to consciousness, conceptual blending choreographs vast networks of conceptual meaning, yielding cognitive products that, at conscious level, appear simple. The way we think is NOT the way we think we think. Everyday thought seems straightforward, but even our simplest thinking is astonishingly complex. (Fauconnier and Turner 2002: v)

\section{Blending-determined semantic extensions}

In order to demonstrate the blending theory at work let us examine the following examples featuring the neosemantic verb to pink:

(11) I saddled up the Olds and drove quickly south on Military Drive in order to keep my date with Bobby. In the process, I pinked a few lights and caused more than one fellow driver to salute me in the traditional way one does to drivers without manners.

(12) I didn't run it, I pinked it. [commenting on passing the intersection on red light]

Both uses of to pink in example (8) and (9) reveal full semantic overlap and designate the event of "crossing an intersection as the traffic light changes from yellow to red." I suggest that the direct motivation for this semantic extension may be a visual blend of two colours - red and white. Nevertheless, even this perceptually-grounded explication of the adnominal verb to pink is insufficient, as the proper semantic description must take into consideration a deeper level of conceptualisation associated with sensory stimuli.

If so, we have to look for an explanation somewhere else. It seems that Fauconnier and Turner's CIT can offer a viable solution in this case. In order to fully understand the extended meaning of the lexeme pink, from which the verb to pink appearing in sentences (11) and (12) has been metonymically converted, one has to integrate two mental spaces construed around the colour concepts WHITE and RED. Figure 3 demonstrates graphically the conceptual blending for these input spaces (this, however, shall be treated as a proposal, one of the many possible mental simulations generated in the blend). Each input is structured by a cultural frame evoking relevant partial information from extralinguistic knowledge pertaining to rich symbolism associated with the colour white and red encoded in and specific to Western culture. Additionally, for the RED input the 'road traffic' frame is activated. The mentally activated elements from the inputs are linked to one another via cross-space mappings based on the relation of disanalogy, and then selectively projected into the blended space depending on their relevance to the conceptualiser and overall context of the utterance, in this case road traffic situation. ${ }^{3}$

\footnotetext{
${ }^{3}$ Note that in the blend, as it has been mentioned before, one may run a number of different simulations producing different new qualities. For instance, if one thinks of the Polish national flag as a blend using the same two input spaces WHITE and RED, the emergent structure is not PINK as in the example analysed here. This is because the process of selective projection of elements from the inputs onto the blend, and subsequently running the blend (elaboration) is
} 


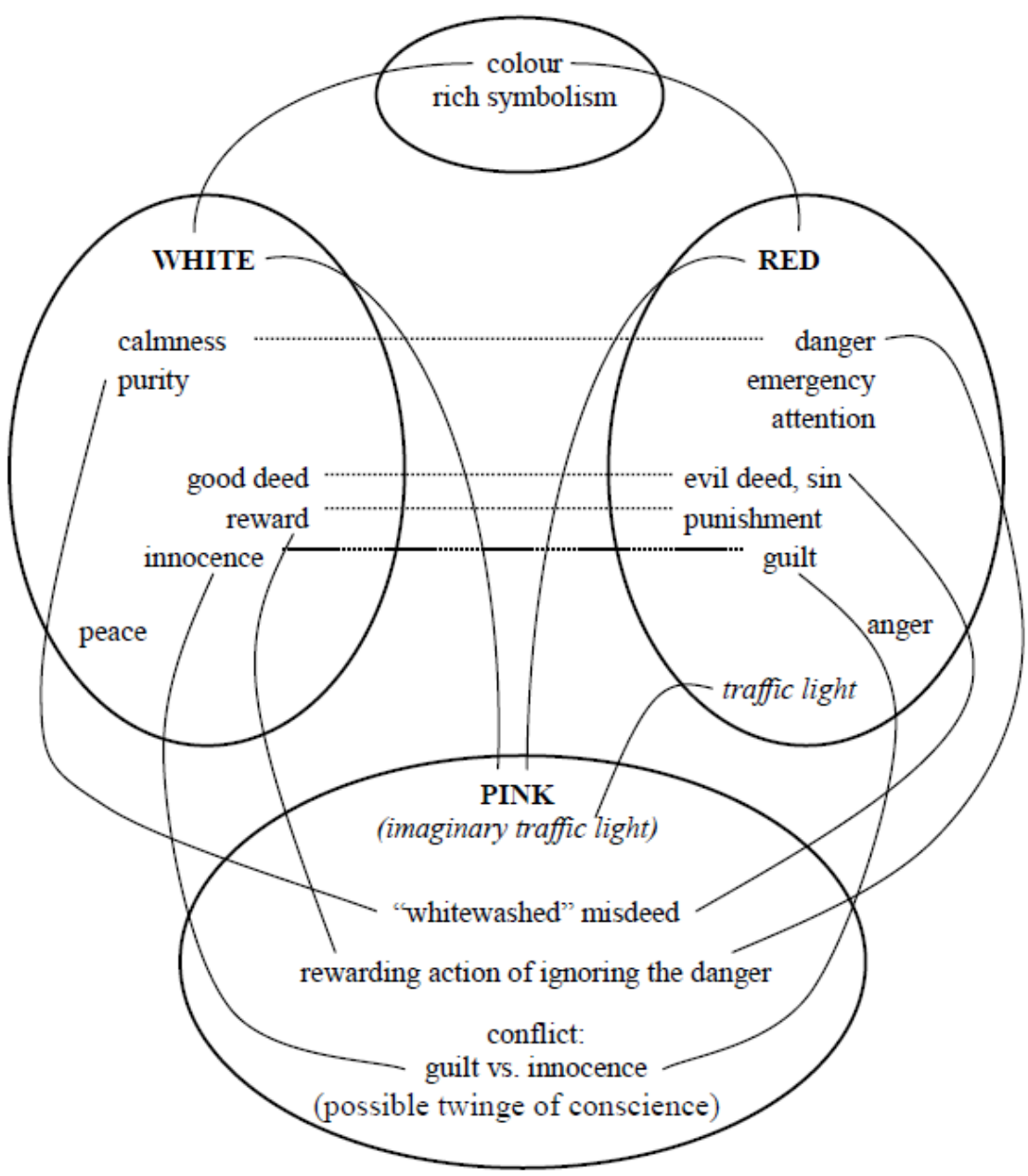

Figure 3: Conceptual Integration Network for the verb to pink

In the blend, which inherits its 'road traffic' frame from the red input, the disanalogous elements from the inputs are compressed into identity (cf. Libura 2007: 42), and thus in the 'road traffic culture' context pink appears to be an illusory traffic light, which allows the hasty driver to cross the intersection although, pursuant to binding traffic regulations, one must not do this due to one's own life threat and possibility of posing a potential risk for other "fellow drivers". Being aware of that fact the driver, upon running a "pink

dependent upon and sanctioned by the activated frames and context of the expression. In the case of the Polish flag the context includes the history and cultural heritage of Poland, whereas for the 'pink light' the context encompasses the cross-cultural symbolism of the colours 'white' and 'red' as well as the 'road traffic' frame. 
light', may suffer from moral remorse; however, performing the action seems for him to be more rewarding than dangerous and, perhaps due to relatively low risk of punishement, the driver feels absolved from his traffic misdemeanour. Consequently, the verb to pink designates the action of passing through an intersection on such a "pink light'.

\section{Context and meaning construction in discourse}

We shall focus now on the process of meaning construction or, as Langacker (2008) calls it, conceptual construction. Says Langacker:

An expression's meaning presupposes an extensive, multifaceted conceptual substrate that supports it, shapes it, and renders it coherent. Among the facets of this substrate are (i) the conceptions evoked or created through the previous discourse; (ii) engagement in the speech event itself, as part of the interlocutors' social interaction; (iii) apprehension of the physical, social, and cultural context; and (iv) any domains of knowledge that might prove relevant. A lexical item does not have a fully determinate meaning. Instead, its semantic value resides in conventional paths of access (some welltrodden, others less so) to open-ended domains of knowledge. Precisely what it means on a given occasion - which portions of this encyclopedic knowledge are activated, and to what degree - depends on all the factors cited. (Langacker 2008: 42)

A "realistic" definition of linguistic meaning that arises in the process of meaning construction, as Langacker calls it, which draws on "open-ended domains of knowledge", has been formulated by him as follows:

[...] besides elements that are indisputably semantic, an expression's meaning includes as much additional structure as is needed to render the conceptualization coherent and reflect what speakers would naively regard as being meant and said, while excluding factors that are indisputably pragmatic and not necessary to make sense of what is linguistically encoded. (Langacker 2008: 42/464)

From this it follows that a major task for the speaker is to form an utterance that will lead to the desired interpretation on the hearer's part. It is precisely the context that helps accomplish this though. The most important aspects of the discourse context relate to the linguistic expressions used in the discourse, as well as those components of general social and cultural knowledge that have indirect impact on the context of a particular usage event. As Gilles Fauconnier (1997) observes

[...] discourse configurations are highly organized and complex within wider social and cultural contexts, and the raison d'être of grammatical constructions and words within them is to provide us with (imperfect) clues as to what discourse configurations to set up. (Fauconnier 1997: 5)

Fauconnier emphasises also the role of full discourse context in the processes of meaning construction, as evidenced by the following quotation:

A language expression $E$ does not have meaning in itself, rather it has a meaning potential, and it is only within a complete discourse and in context that the meaning [concrete sense] will actually be produced. (Fauconnier 1997: 37) 
The foregoing discussion makes it possible for us to schematically illustrate the nature of meaning construction incorporating contextual factors (on the basis of a modified version of the model proposed by Evans and Green 2006: 458):

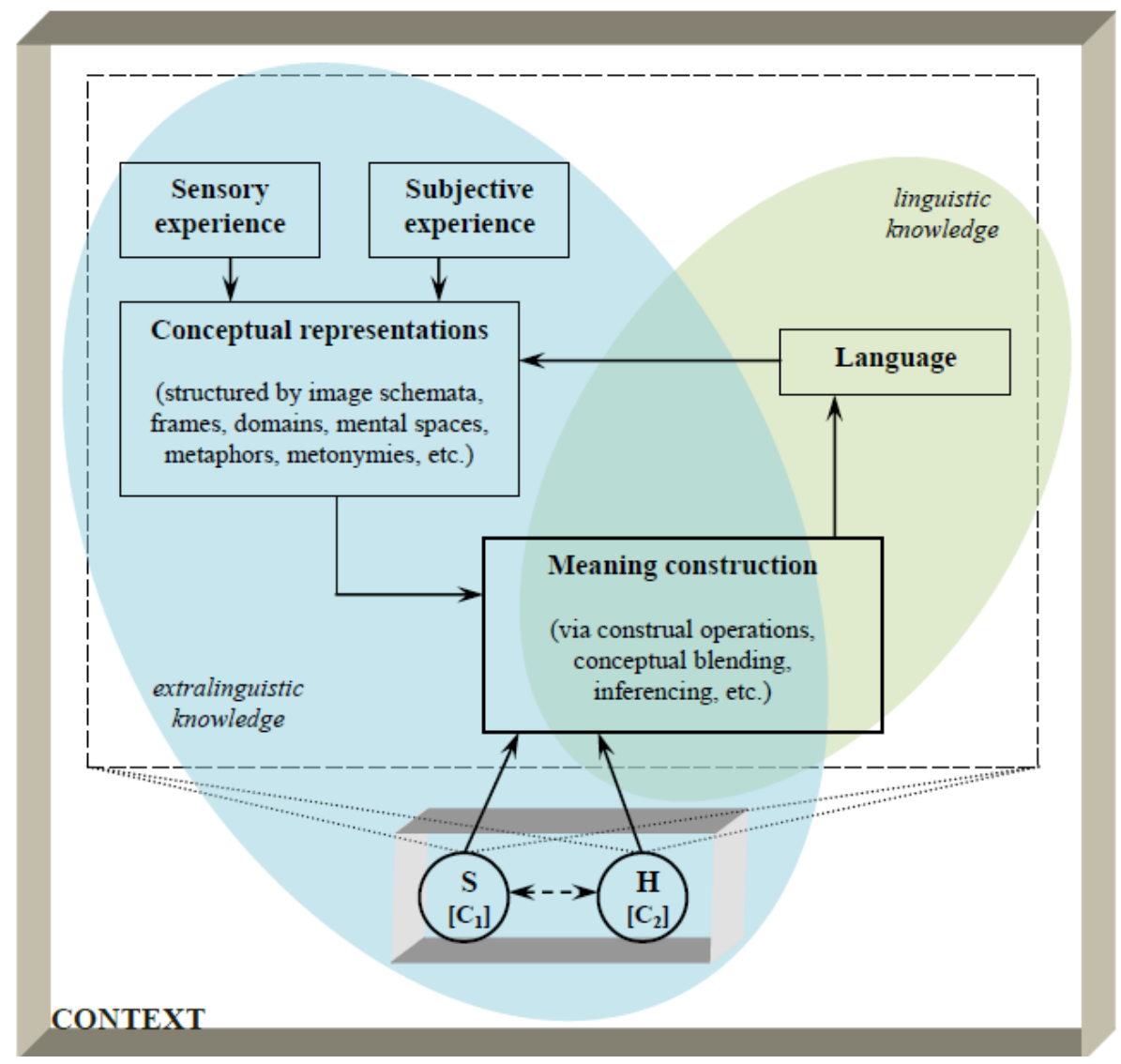

Figure 4: Meaning construction embedded in context

As shown in Figure 4. the whole meaning construction process is anchored in and guided by context. In the process, the interlocutors, a speaker $(\mathrm{S})$ and a hearer $(\mathrm{H})$, who at the same time are subjects of the conceptualisation (i.e. they are conceptualisers $\mathrm{C}_{1}$ and $\mathrm{C}_{2}$ ), perceive (and produce) sensory stimuli (e.g. acoustic signals, visual stimuli, etc.) of the external world, which combined with the subjective experience of their introspective view on the world, give rise to mental representations of the world. Those representations constitute parts of the conceptualisers' encyclopaedic knowledge which is structured by frames, domains, ICMs, mental spaces, etc. Motivated by language, these representations are then subject to dynamic processing involving basic construal strategies and operations such as profiling or conceptual integration. As a result, meanings are produced, which in turn contribute to and affect language itself, e.g. through meaning extension, language change, etc. This model of language is designed to 
account for meaning construction, as determined by both linguistic and extralinguistic context. The former relates to language and linguistic knowledge, while the latter encompasses such dimensions as physical context (sensory experience and the interaction between the interlocutors) and knowledge context (cultural, social and encyclopaedic knowledge). We wish to stress at this point that the graphical representation of meaning construction provided here is largely an extensively simplified picture of the whole process and by its very nature cannot account for all the intricacies pertaining to it. Nonetheless, it allows one to envisage how context, particularly in its two main facets (linguistic and extralinguistic), is related to specific aspects of the meaning construction process.

\section{Current Discourse Space}

The foregoing discussion has revealed that in Cognitive Linguistics the pragmatic aspects are an integral parcel of the semantic value of an expression. More concretely, cognitive linguists argue that meaning, while it is relatively stable and evokes a certain range of knowledge, is not completely fixed and given in the text explicitly, but rather is construed on-line on the basis of hints in the form of language expressions and discourse context used (cf., inter alia, Langacker 1987: 425-426 and 2008: 39; Taylor 2002: 107; Evans and Green 2006: 352; Libura 2007:15).

The issue requiring characterisation now is the question of how discourse is comprehended in cognitive paradigm. According to Langacker (2008: 457), a discourse comprises a series of usage events, i.e. "the instances of language use in all their complexity and specificity" or, put differently, a usage event embraces "an expression's full contextual understanding, a portion of which can be identified as linguistic meaning" (p. 465). A discourse is thus a highly interactive process on the part of at least two interlocutors, a speaker and a hearer, in which the speaker exerts some influence on an actual or imagined hearer. A particular usage event is never absolutely identical for both the speaker and hearer, but still, for the communication to be successful, substantial overlap of some salient aspects of the scene as construed by the speaker and hearer is necessary (cf. Taylor 2002: 108).

In his attempt to provide a common ground for interlocutors engaged in discourse as well as for discourse interpretation, Langacker $(2005,2008)$ introduces the notion of Current Discourse Space (CDS):

It [CDS] comprises everything presumed to be shared by the speaker and hearer as the basis for communication at a given moment. Part of the CDS, of course, is the current discourse itself, including both previous usage events and any that might be anticipated. Also part of the CDS are other mutually evident aspects of the transient context, as well as any stable knowledge required for their apprehension or otherwise invoked. All of these may figure in an expression's full contextual understanding and in those portions that constitute its linguistic meaning. (Langacker 2008: 466)

The idea of Current Discourse Space coded by linguistic structure is presented graphically in Figure 5. 


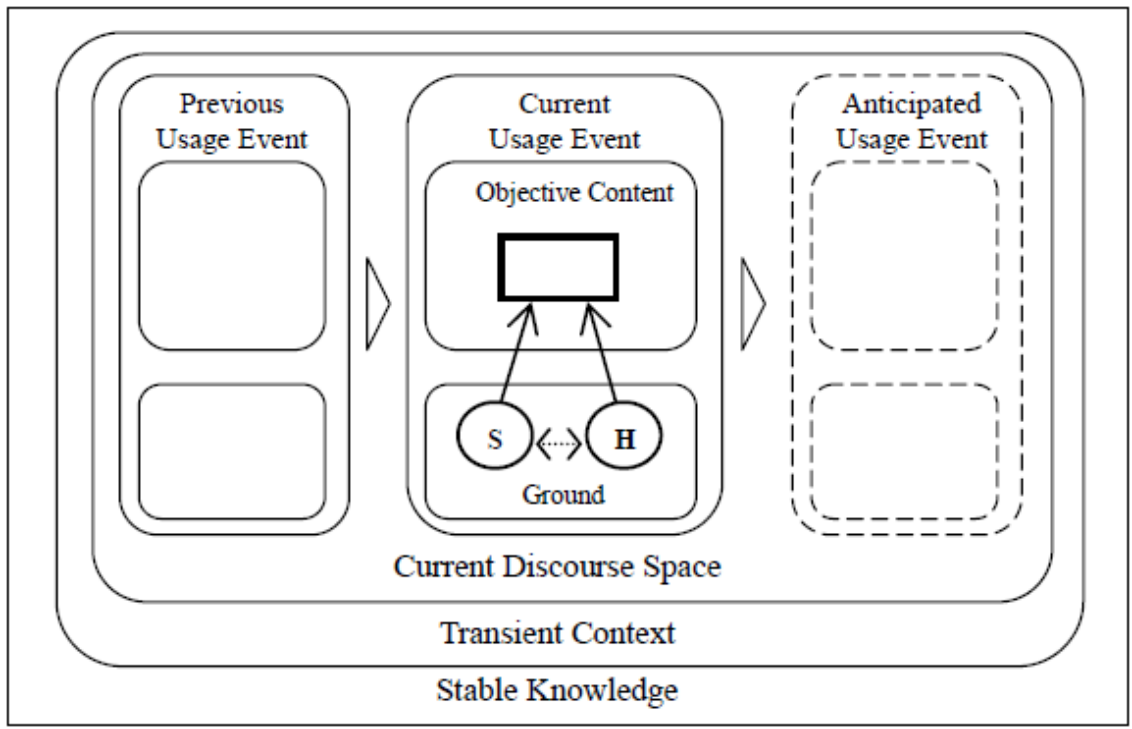

Figure 5: Standard model of Current Discourse Space

A key factor in establishing the linguistic meaning in this model is the interaction between the speaker and the hearer, both of whom actively evaluate the other's knowledge and intentions. Since the hearer interprets the meanings conveyed to him by the speaking entity, the proper understanding of a linguistic expression requires the hearer to actively participate in the ongoing discourse as well as to put mental effort in establishing the actual meaning of this expression. As a consequence, the information included in the message conveyed to him by the speaker must be confronted with his vast repository of encyclopaedic knowledge (cf. Langacker 2008: 464-465). Simultaneously, context in all its dimensions as well as the discourse context (previous usage events and anticipations relating to potential successive usage events) facilitate or help to structure the conceptualisations arising in the speaker's mind, eventually enabling the hearer to construe the meaning of the relevant expression.

\section{Integrated (CIT and CDS-based) meaning analysis}

On the basis of the foregoing discussion we argue for an integrated meaning analysis of nesemantic noun-to-verb conversions (see Figure 6. depicting schematically the process of meaning construction in discourse) in that we apply the notion of CDS and combine it with our observation that an expression's meaning arises as a result of conceptual blending of the meaning potentials of the lexical concepts used in a particular utterance (represented by the upper ellipse). Specifically, while construing meaning in discourse, the interlocutors develop conceptualisation of the scene coded by linguistic utterances. Similarly to the conceptual arrangement (Langacker 1999: 203-205, see also Figure 2.), where conceptualisers are able to construe conceptualisations of only those entities and 
relations that are in the immediate scope of the scene construed, in unfolding discourse, only a part of the utterance that is within what Langacker (2005: 130) refers to as "viewing frame", or "immediate scope" (IS) of a given expression (current usage event) is processed. Within the viewing frame, in turn, a profile of a particular expression is put into focus of attention. Langacker suggests that it is the speaker who directs the attention of the hearer to the conceptual content profile of a linguistic unit by using a specific expression (ibid.). Since linguistic units in Cognitive Linguistics are held to constitute bipolar symbolic assemblies comprising the semantic and phonological poles, then the expression's meaning emerging in the process of conceptual blending of semantic potentials of lexical concepts abstracted for a particular expression constitutes the semantic pole of the expression in the speaker's focus of attention (cf. also e.g. Kardela 2007).

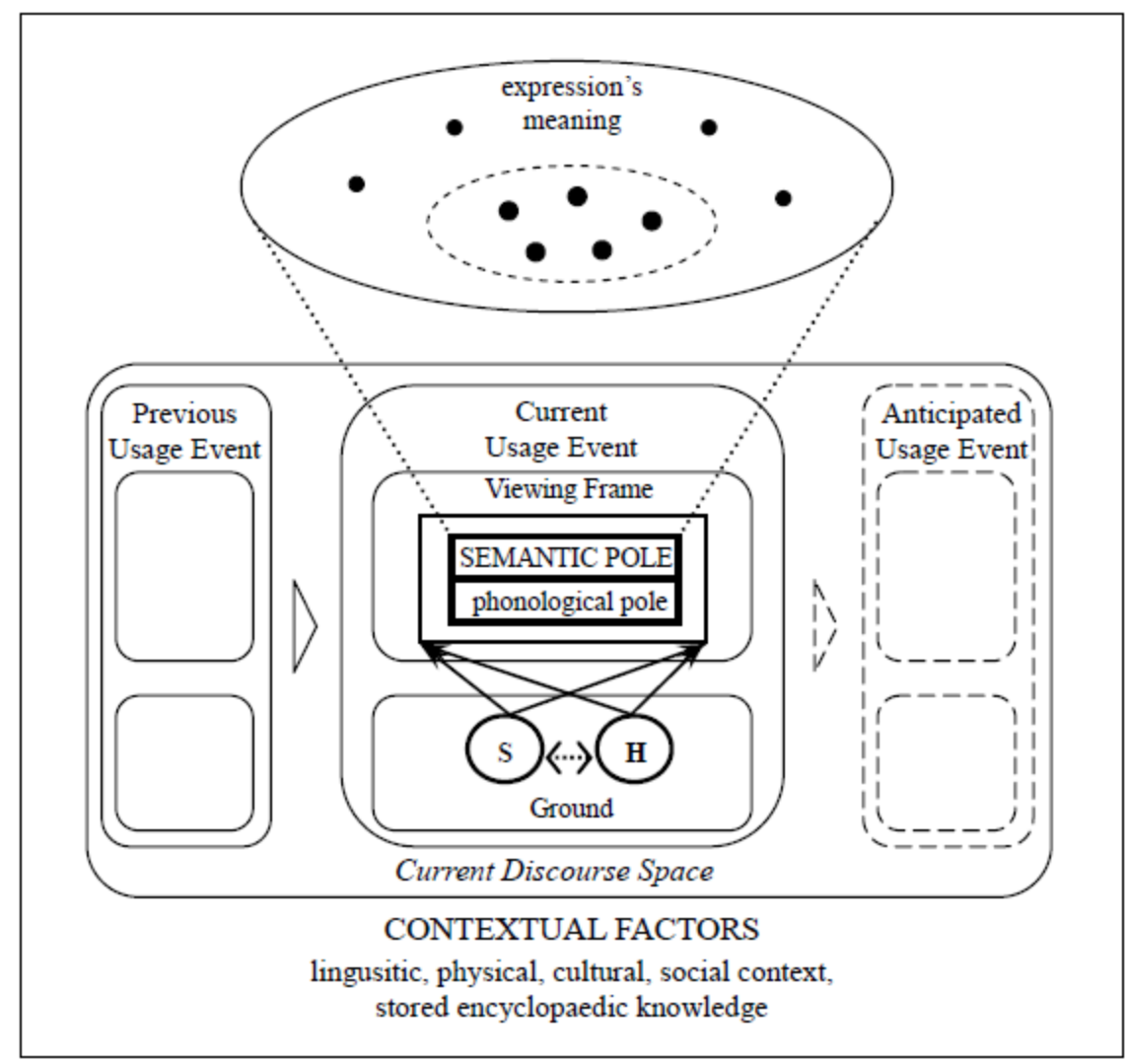

Figure 6: Discourse-guided meaning construction

At this point we want to emphasise that only selected parts of activated meaning potentials (presented here as elements) that are sanctioned by linguistic and extralinguistic context are projected into the blend and contribute to the utterance meaning. After the composition of these selected elements in the blend, contextual 
factors prompt for the completion of the structure in the blend, giving rise to novel, emergent semantic constituents (encapsulated in the dotted-line ellipse). Then, it is only in the process of elaboration, i.e. mental simulation of events based on the conceptual structure assembled in the blend that the actual meaning of a particular expression is produced.

Returning to the models of meaning construction embedded in context (see Figures 4. and 5.) we want to reiterate that in these models speaker and hearer, both acting as conceptualisers and belonging to the ground of the ongoing meaning construction process, play a vital role in it, as both construe mental representations of the world on the basis of linguistic expressions used in the discourse. The task of the speaker is to design such a linguistic utterance, i.e. to encode linguistically his or her mental representations of a particular scene in such a way that the speaker is able to decode it properly and conceptually arrive at mental representations as close as possible to those intended by the speaker. This task is not simple, however, since mental representations are unstable and depend upon the encyclopaedic knowledge of a relevant conceptualising subject; also the encyclopaedic knowledge which involves conceptualiser's subjective experience of the world will differ from one conceptualiser to the next. Still, as Langacker (2008: 466) points out, a substantial overlap of the scene as construed by the speaker and hearer is sufficient to produce a conceptualisation along with the coherent meaning of the linguisit utterance.

\section{Contextual constraints on dynamic construal of meaning}

As we could observe in the foregoing, neosemantic forms such as noun-to-verb conversions derive their meaning from the overall meaning of the utterance in which they were used. This points to the fact that the novel sense is strongly embedded in specific context of its use. Apart from determining meaning construction, context imposes certain, sometimes even severe, constraints on the dynamic construal of meaning. These contextual constraints, as Croft and Cruse (2004: 102-103) label them, ${ }^{4}$ involve:

(i) linguistic context, which imposes constraints on the meaning construction process due to previous discourse configurations (or basically what we referred to previously as discourse context), immediate linguistic environment (direct phrasal or sentential context) and the type of discourse (including genre, register and thematic field);

(ii) physical context, which draws on any perceptual stimuli having influence on discourse participants in their immediate surroundings;

(iii) social context, which encompasses situational circumstances and the social relations between the discourse participants;

\footnotetext{
${ }^{4}$ The contextual constraints introduced by Croft and Cruse (2004) relate to Clark's (1996: 92ff.) conception of common ground. Langacker's $(2005,2008)$ notion of Current Discourse Space may be perceived, de facto, as an instance of a common ground with shared actional, personal, perceptual and knowledge basis, as well as mental representations established by and between interlocutors for communicative purposes (cf. Clark 1996: 94-96).
} 
(iv) stored knowledge, i.e. all expressions uttered in the course of the discourse are processed against the background of stored experiences and knowledge which, as it were, 'supervise' the meaning construction process and sanction or inhibit particular construals.

All of these constraints exert strong influence on the dynamic process of meaning construal. This is made particularly evident, for instance, in the case of the verb to obama, which is popularly used in a number of different and largely incompatible senses. Below we present just a sample of usages:

(13) a. Hey Jimmy, I need you to obama my car.

[to obama - to fix]

b. If you have poor vision, wearing glasses will obama your eyesight.

[to obama - to improve]

(14) His fear to obama the change needed prompted him to hire an entire new team. [to obama - to fail to fix something by relying on the same people who destroyed it]

(15) Don't Obama our last roll of toilet paper, we can't buy more until tomorrow. [to obama - to waste something]

(16) We are all going to suffer if the Democrats keep obamaing our tax dollars. [to obama - to unjustly take something away from someone]

(17) Oh my gosh, we were playing team rummikub the other night and my partner Fred totally obama'd this massive move and made me take all the blame. [to obama - to blame someone else for someone's own mistakes]

(18) I just obama'd a fly man, it was awesome!

[to obama - to kill a fly in midair]

Although the noun-to-verb conversion to obama instantiates a simple metonymic extension, following the schema agent involved in the action for the action, all uses in examples (13) through (18) refer to a number of totally different activities. This should not be surprising, since the incumbent US-president Barrack Obama is a public figure whose actions are carefully monitored by both his adherents and opponents and extensively commented on. Very often the name of the President emerges in people's everyday discussions serving as a certain point of reference. The examples invoked demonstrate eloquently the importance of discourse context mediation in the process of meaning construction of novel linguistic expressions. In order to interpret the verb to obama in all these examples, the context of speaker's stored knowledge pertaining to current affairs of state must be seen to play a particularly important role.

The sense of to obama in (13) might have been coined by the President's followers satisfied with the policy of his administration which is perceived as the cure to all problems of the state; hence by virtue of conversion the verb designates the action of fixing something (13a). The sense in (13b) seems to be the case of a semantic extension from (13a) via metaphoric generalisation. Curiously enough, the sense in (14) is just the 
opposite of (13); it has undergone a semantic narrowing, since it does not refer to "failing to do something" generally, but is restricted to those cases when the failure is the result of entrusting someone who contributed to the failure with a task to repair it. This clearly alludes to the oil spill disaster in the Gulf of Mexico that happened last year, and when the president charged the same oil concern that was responsible for the catastrophe with the task to rectify their disastrous error.

Senses (14) through (17) are generally 'negative senses' in that the actions described by them are considered to be detrimental for the overall welfare of people or things affected by them. These could have been coined by speakers displeased with the President Obama or his policy. For instance, the meaning of to obama in (15) refers to someone's subjective impression that the President throws tax payers' money around without much care. In (16) the verb has been used in such a way that it insinuates that the President (who stands metonymically for the whole government) takes away money from those that earn it through hard work and gives it to those who don't deserve it. ${ }^{5}$ This sense appears to be also related to that in (15). To obama in (17) also invokes the speaker's prejudice towards the President's political performance and here the verb does not pertain strictly to the domain of political action but is extended to other domains of action (e.g. gaming situation). The motivation for this sense given by Urban Dictionary is that it refers to the way how the President is reported to talk grandly for hours about a future move he is going to make and after making the move he realises it was wrong, but then he starts blaming it on someone else, usually the opposite party.

The meaning of to obama in (18) is different in this regard from all the previous examples in that it is rather a neutral, or at most a humorous term, based on a real incident from June 2009, when President Obama during a live interview for CNBC channel killed a fly in the studio.

\section{Conclusion}

To construct a discourse that will mediate the meaning construction of a neosemantic expression as envisaged in this article, discourse participants, i.e a speaker and a hearer must invoke an appropriate context, relevant to the expression used. As a matter of fact, it seems, the global discourse context arises as the effect of merging different subcontexts pertaining, inter alia, to general encyclopaedic and cultural knowledge of discourse participants, common knowledge shared by speaker and hearer in the current discourse space, the activated domain of the unfolding discourse and discourse genre, the socio-cultural settings of the discourse, previous and current usage events with special emphasis on the immediate linguistic co-textual environment of the profiled expression in the current usage event. These different aspects of context are subject to ongoing

\footnotetext{
${ }^{5}$ This particular usage is motivated by the bias of the speaker-coiner towards the President and may refer to the democrat economic crisis plan from 2008/2009 resulting in pumping billions of dollars into financial markets in an attempt to stop the economic free-fall. The negative attitude of the speaker encoded in the verb may affect the way how a potential hearer will perceive the actual person whose name was used to designate the action. This seems to constitute an interesting socio-cultural 'side effect' of the otherwise neutral linguistic phenomenon such as noun-to-verb conversion.
} 
change as each successive usage event 'updates' the overall context which has direct influence on the online meaning construction of the utterance deployed in the discourse (cf. also Gumperz 1992 and Roberts 2004).

The discourse context in all its facets (linguistic, sentential, physical, cultural, social, encyclopaedic knowledge, etc.) facilitates structuring the unfolding CDS and enables the hearer to focus on the profiled expression (e.g. neosemantic noun-to-verb conversion) within a particular utterance. Of course, the context as perceived by the speaker and hearer may differ slightly owing to different construals of the scene or stored encyclopaedic knowledge, which is primarily due to different subjective experiences of discourse participants; however, a substantial overlap of their different perspectives is sufficient so that we could speak of a common contextual space in which discourse is embedded.

\section{References}

Clark, Eve V. \& Herbert H. Clark (1979). "When nouns surface as verbs”. Language, 55, 767-811.

Clark, Herbert H. (1996). Using Language. Cambridge: Cambridge University Press.

Coulson, Seana (2001). Semantic Leaps. Frame-shifting and Conceptual Blending in Meaning Construction. Cambridge, New York, Melbourne, Madrid, Cape Town, Singapore, Sao Paulo: Cambridge University Press.

Croft, William \& Alan D. Cruse (2004). Cognitive Linguistics. Cambridge: Cambridge University Press.

Dirven, René \& Marjolijn Verspoor (2004). Cognitive Exploration of Language and Linguistics. Amsterdam, Philadelphia: John Benjamins Publishing Company.

Elsen, Hilke (2004). Neologismen. Formen und Funktionen neuer Wörter in verschiedenen Varietäten des Deutschen. Tübingen: Gunter Narr Verlag.

Evans, Vyvyan and Melanie Green (2006). Cognitive Linguistics: An Introduction. Edinburgh: Edinburgh University Press.

Fauconnier Gilles (1985). Mental Spaces. Cambridge, Mass.: MIT Press.

Fauconnier, Gilles (1994). Mental Spaces: Aspects of Meaning Construction in Natural Language. Cambridge: Cambridge University Press.

Fauconnier, Gilles (1997). Mappings in Thought and Language. Cambridge: Cambridge University Press.

Fauconnier, Gilles \& Mark Turner (1994). "Conceptual Projection and Middle Spaces". San Diego: University of California, Department of Cognitive Science Technical Report 9401. Retrieved March 15, 2010, from http://markturner.org.

Fauconnier, Gilles \& Mark Turner (1998). "Principles of Conceptual Integration". In J.P. Koenig (Ed.), Discourse and Cognition (269-283). Stanford: Center for the Study of Language and Information.

Fauconnier, Gilles \& Mark Turner (2002). The Way We Think. Conceptual Blending and the Mind's Hidden Complexities. New York: Basic Books.

Fauconnier, Gilles \& Mark Turner (2007). Conceptual integration networks. In V. Evans, B. K. Bergen \& J. Zinken (Eds.), The Cognitive Linguistic Reader (360-419). London, Oakville: Equinox Publishing Ltd. 
Grabias, Stanisław (1980). O ekspresywności języka. Ekspresja a słowotwórstwo. Lublin: UMCS.

Gumperz, John J. (1992). "Contextualization and understanding”. In Ch. Goodwin \& A. Duranti (Eds.), Rethinking Context: Language as an Interactive Phenomenon (229252). Cambridge: Cambridge University Press.

Herberg, Dieter \& Michael Kinne (1998). Neologismen. Heidelberg: Groos.

Kardela, Henryk (2006). “(Nie)podobieństwa w morfologii: amalgamaty kognitywne”. In H. Kardela, Z. Muszyński \& M. Rajewski (Eds.), Kognitywistyka: Podobieństwo (195-210). Lublin: Wydawnictwo UMCS.

Kardela, Henryk (2007). "Good' revisited: A mental space analysis”. In U. Magnusson, H. Kardela \& A. Głaz (Eds.), Further Insights into Semantics and Lexicography (291-303). Lublin: Wydawnictwo UMCS.

Kemmer, Suzanne (2003). "Schemas and lexical blends". In G. Radden \& H. Cuyckens (Eds.), Motivation in Language. Studies in Honor of Günter Radden (69-95). Amsterdam, Philadelphia: John Benjamins.

Langacker, Ronald W. (1987). Foundations of Cognitive Grammar, vol. 1: Theoretical Prerequisites. Stanford: Stanford University Press

Langacker, Ronald W. (1991). Concept, Image, and Symbol: The Cognitive Basis of Grammar. Berlin: Mouton de Gruyter

Langacker, Ronald W. (1999). Grammar and Conceptualization. Berlin, New York: Mouton de Gruyter.

Langacker, Ronald W. (2005). Wykłady z gramatyki kognitywnej. Lublin: Wydawnictwo UMCS

Langacker, Ronald W. (2008). Cognitive Grammar. A Basic Introduction. New York: Oxford University Press

Langlotz, Andreas (2006). Idiomatic Creativity. A cognitive-linguistic model of idiomrepresentation and idiom-variation in English. Amsterdam, Philadelphia: John Benjamins Publishing Company.

Libura, Agnieszka (2007). Amalgamaty kognitywne w sztuce. Kraków: Universitas.

Lieber, Rochelle (2004). Morphology and Lexical Semantics. Cambridge: Cambridge University Press.

Roberts, Craige (2004). “Context in dynamic interpretation”. In L. R. Horn \& G. Ward (Eds.), The handbook of pragmatics (197-220). Oxford: Blackwell Publishing.

Taylor, John R. (2002). Cognitive Grammar. Oxford: Oxford University Press.

Taylor, John R. (2003). Linguistic Categorization: Prototypes in Linguistic Theory, 3rd ed. Oxford: Oxford University Press.

Twardzisz, Piotr (1997). Zero Derivation in English: A Cognitive Grammar Approach. Lublin: Wydawnictwo UMCS.

Veale, Tony \& Cristina Butnariu (2010). Harvesting and understanding of on-line neologisms. In A. Onysko \& S. Michel (Eds.), Cognitive Perspectives on Word Formation (399-420). Berlin, New York: Mouton de Gruyter. 


\title{
Sources of linguistic examples
}

The Rice University Neologisms Database. Retrieved February 10, 2011, from http://neologisms.rice.edu/index.php.

Urban Dictionary. Retrieved February 10, 2011, from http://www.urbandictionary.com/.

\begin{abstract}
About the author
The author is affiliated with the Department of Applied Linguistics at Maria CurieSkłodowska University, Lublin. He has recently defended his Ph.D. dissertation entitled Context-Dependent Meaning. A Cognitive Linguistic Analysis of Noun-to-Verb Conversion Phenomena in English. His current research interest centres on the cognitive mechanisms of conversion and neosemantisation processes. However, he is also interested in contrastive and translation studies; his M.A. paper concerned the analysis of German and Polish translations of English science fiction neologisms.
\end{abstract}

